\title{
INTRODUCTION TO THE SPECIAL SECTION
}

Small and medium-sized enterprises (SMEs) have always played an important role in European economies. The experience of certain countries and regions shows that the activities of dynamically growing, competitive SMEs can be a basis for rapid economic growth. This is even truer for internationalised SMEs, which are usually more competitive, innovative and successful, than their counterparts which concentrate their activities fully in the domestic economy. In the Visegrad countries (Czechia, Hungary, Poland and Slovakia), SMEs, at least in terms of their numbers, represent a large part of the economy, even in a wider EU-comparison. However, the level of internationalisation of Visegrad SMEs is among the lowest in the EU. This specific feature was the motivation to have a closer look at the internationalising SMEs of the region in this special section. Research on this topic has traditionally been constrained by the lack of comparable data, which explains why the articles here rely on many different sources of information and methods, including statistical analysis and industry and company case studies.

The majority of the articles were presented at an international research seminar organised by the Foreign Direct Investment Research Group at the Centre for Economic and Regional Studies of the Hungarian Academy of Sciences. The workshop focused on the internationalisation of SMEs in the Visegrad countries. The authors of the articles in this special issue are indebted to the participants of the research seminar for their valuable comments, helping to transform their findings into research papers.

The articles address the issue of SME internationalisation from different angles. Andrea Éltető's article compares SMEs' export behaviour during the crisis in three larger regions in the European periphery. She denotes interesting differences in SME internationalisation behaviour even within these three regions and shows that the geographical "re-targeting" of exports towards non-EU countries for SMEs was only a temporary phenomenon.

Miklós Kozma and Magdolna Sass analysed two important features of international new ventures based on Hungarian company cases in the IT and biotechnology industries. They show that the Hungarian company cases reinforce the findings of empirical studies on INVs: they consider the global market as their target market and they rely to a great extent on networks, at least in the initial stages of 
their internationalisation. However, the analysis of the odd-ones-out hints to the possible existence of specific features of post-transition INVs.

Miklós Stocker's article relied on the statistical analysis of Hungarian INVs, analysing in detail their survival, growth and performance through grouping them in three clusters. The three clusters (sustainable INVs, terminated INVs, and INVs which refocus on the domestic market after initial exports) differ from each other significantly, allowing a deeper analysis of the characteristics of Hungarian INVs.

Global production networks (GPN) represent today the leading form of governance in production in several industries. The opportunities offered to SMEs in GPNs differ widely from country to country, from industry to industry, and even within the same country and industry from GPN to GPN. Jana Vlčková analyses the role of Czech SMEs in medical technology GPNs, and shows how GPNs shape this industry in Czechia. She underlines the limited opportunities offered to SMEs in the participation in GPNs in the analysed industries and the limited capacities due to which even these opportunities cannot be realised.

The articles presented in this special section contribute to our knowledge about SME internationalisation in the Visegrad countries, especially Hungary. The "deviations" from what can be expected based on the theoretical models calls the attention to the fact that there are certain country or region specific features, which deserve further analysis.

Magdolna Sass

Centre for Economic and Regional Studies of the Hungarian Academy of Sciences

Guest editor of the special section

Open Access. This is an open-access article distributed under the terms of the Creative Commons Attribution 4.0 International License (https://creativecommons. org/licenses/by/4.0), which permits unrestricted use, distribution, and reproduction in any medium, provided the original author and source are credited, a link to the $\mathrm{CC}$ License is provided, and changes - if any - are indicated. (SID_1) 